\title{
ABSTRACTS
}

(This section of the JouRNAL is published in collaboration with the two abstracting Journals, Abstracts of World Medicine, and Abstracts of World Surgery, Obstetrics, and Gynæcology, published by the British Medical Association. The abstracts are divided into the following sections : toxicology ; industrial physiology ; industrial lung disease ; industrial skin diseases; accidents and orthopadic surgery ; industrial ophthalmology ; environment; general. Not all sections will necessarily be represented in any one issue)

\section{INDUSTRIAL OPHTHALMOLOGY}

Optic Neuritis from Cold Permanent Wave. RoBSON, J. T., and CAmeron, W. (1949). Northw. Med., Seattle, 48, 701.

The authors record 2 cases (in a mother and daughter, living apart) of bilateral optic neuritis which they consider to have been caused by thioglycollic acid contained in a hair-curling ("cold permanent wave") lotion. They review the literature concerning toxic effects from this substance, of which dermatitis appears to be the only one previously described. The first patient, the daughter aged 23, used the lotion 3 times during a 12-month period and developed optic neuritis in the left eye 3 months after the last application and in the right eye 6 months later, vision being reduced to $1 / 60$ and $2 / 60$ respectively. The mother, aged 54 , used the lotion 4 times over a 22-month period and developed optic neuritis in the right eye 6 months after the first application and in the left eye 11 months later, vision being almost completely lost in the right and reduced to $1 /{ }_{60}$ in the left. In both cases all other findings, which included the usual routine investigations, were negative. Both later showed bilateral optic atrophy.

[Although the manufacturers of the lotion paid compensation without court procedure, the æatiological role of the thioglycollic acid must be considered unproven. The long interval between the first use of the lotion and onset of symptoms is a point against, though not excluding, thioglycollic acid as the cause. Moreover, where there is such a long interval (in one case 11 months and in the other 6 months) between the involvement of the two eyes, it is difficult to exclude disseminated sclerosis as the cause. However, in future in any obscure case of optic neuritis, the possibility of a "cold permanent wave" lotion being the cause should be carefully considered and the report of further cases will be awaited with interest.] M. H. Pappworth.

\section{TOXICOLOGY}

The Effect of BAL on Experimental Lead, Tungsten, Vanadium, Uranium, Copper and Copper-Arsenic Poisoning. Lusky, L. M., Braun, H. A., and LAUG, E. P. (1949). J. industr. Hyg., 31, 301.

The authors have previously reported that BAL $(2,-3$ dimercaptopropanol) enhances the toxicity of lead salts administered intramuscularly and intraperitoneally to rabbits. In this paper they describe experiments carried out to determine whether this increased toxicity is due to the formation of a more toxic BAL-lead-salt complex or to an increase in the rate at which the lead salt is mobilized from the site of injection. Acute lead poisoning was produced in rabbits 8 to 10 weeks old by a single intravenous injection of $1 \%$ solution of lead acetate ( 20 to $40 \mathrm{mg}$. per $\mathrm{kg}$. body weight). Immediately after this an intravenous injection of $3 \%$ aqueous solution of BAL ( $30 \mathrm{mg}$. per kg.) was given, and 6 hours later a subcutaneous injection of BAL in oil ( $30 \mathrm{mg}$. per $\mathrm{kg}$.). Further injections of $15 \mathrm{mg}$. per kg. of BAL in oil were then given twice daily on the $2 \mathrm{nd}, 4 \mathrm{th}, 6 \mathrm{th}, 8 \mathrm{th}$, and 10 th days, and subsequently every third day during the 29-day experimental period. A comparison of the mortality curves in control and treated animals showed that BAL reduced the toxicity of intravenously administered lead acetate and prevented the progressive cachexia characteristic of plumbism. The authors conclude that the increased toxicity in BAL-treated animals which have received lead intramuscularly or intraperitoneally is unlikely to be due to the formation of a more toxic BAL-lead-salt complex, but may be due to the rapidity with which lead is mobilized from the site of injection, causing a breakdown in the normal mechanism of lead metabolism. Estimation of the lead content of bone showed a significant difference between untreated and BAL-treated rabbits, the bones of which contained smaller concentrations of lead. It is unknown whether BAL prevents bone storage of lead or whether it removes lead from the bones after storage.

In experiments on adult rabbits acute tungsten poisoning was produced by the intramuscular administration of a $10 \%$ solution of sodium tungstate, animals given a dose of $110 \mathrm{mg}$. per $\mathrm{kg}$. dying within 5 hours. A single dose of BAL ( $30 \mathrm{mg}$. per kg.) in oil intramuscularly, given within 20 minutes of the tungstate injection, saved all rabbits from its toxic effects. In experiments on copper poisoning, groups of adult rabbits were given single intravenous injections of a $1 \%$ aqueous solution of cupric sulphate. The average survival time of 15 animals after a dose of $20 \mathrm{mg}$. per $\mathrm{kg}$. was 15 minutes. The effect of BAL treatment was spectacular. With a single intravenous injection of BAL $(30 \mathrm{mg}$. per $\mathrm{kg}$.) given within 3 minutes of the injection of cupric sulphate : only 1 animal died and its life was prolonged by 32 hours. Rabbits receiving $20 \mathrm{mg}$. per $\mathrm{kg}$. of cupric sulphate were saved by a single intramuscular injection of $30 \mathrm{mg}$. per 
$\mathrm{kg}$. of BAL in oil. In experiments in which the right carotid artery and the trachea were cannulated, $20 \mathrm{mg}$. per $\mathrm{kg}$. of cupric sulphate was given intravenously. In approximately 15 minutes the blood pressure fell to zero, no pulse was recorded, and respiration ceased. BAL (30 mg. per kg.) given intravenously resuscitated the animal immediately. BAL also exerted a therapeutic effect on acute cupric arsenite poisoning in adult rabbits produced by the oral administration of a $5 \%$ suspension of Paris green. While without BAL a dose of $25 \mathrm{mg}$. per $\mathrm{kg}$. was fatal to 15 of 18 animals, 13 of 18 were saved by a subcutaneous dose of BAL in oil. However, BAL did not decrease mortality or prolong life in animals given $30 \mathrm{mg}$. per $\mathrm{kg}$. of Paris green.

BAL had no therapeutic effects on acute vanadium poisoning, and was similarly ineffective in the treatment of rabbits poisoned by the subcutaneous injection of $1 \%$ solution of uranium nitrate.

M. W. Goldblatt.

Lead Poisoning in the Pottery Industry. D'OnOFRIo, V. (1949). Rass. Med. industr., 18, 155.

Lead glazes have been used in ceramics from the earliest times and the author reports 22 cases of the poisoning which occurred in an Italian factory making glazed tiles for mosaic work. The glazes are compounded of a silicate, an alkali, and a fusing substance such as borax, litharge, or fluorite, to which various pigments are added. The constituents are reduced to powder form before mixing and are then fused in a muffle furnace or other type of oven. The fused mixture is poured into water forming the frit, a borosilicate which is granular and very fragile. The material obtained in this way, either in powder form or as a watery suspension, is now applied with a brush or spray to the articles to be glazed.

If litharge has been used, the frit will contain a borosilicate of lead; if the proportion of silica in relation to the lead compound is sufficiently high, then the lead silicate formed is only slightly soluble in acids. The proportion of lead found on analysis of various types of frit used in the factory concerned varied from 10 to $40 \%$ and their solubility in acids was found to decrease as the proportion of base to acid reached or exceeded 2 to 1 . It is desirable to have all the lead bound as a silicate.

Many workers were admitted to hospital with a history of colic, dyspepsia, constipation, and occasionally asthenia and undue fatigue. They were found to be suffering from secondary anaemia with punctate basophilia associated with leucopenia and relative lymphocytosis, while coproporphyrinuria in excess of normal was also found. It was found that in the processes of pulverization of the frit and its application in suspension to the articles to be glazed some quantity of dust or liquid escaped and contaminated the working-places. Although exhaust ventilation was used in the spraying shed and the employees wore masks and protective clothing, these precautions did not provide complete protection because inhalation of dust from particles deposited and dried on the clothing could not be avoided when this was put on or discarded. Some of the glaze also came off the articles to which it was applied as these were taken to the furnaces and an additional hazard derived from the fact that some workers brought in food which was eaten at or near the working sites. Complete protection is presumably only possible in fully enclosed plant, provision of which is too costly for many firms. Periodic medical examination of employees is therefore essential.

G. C. Pether.

Mercury Poisoning from Fingerprint Photography. An Occupational Hazard of Policemen. AGATE, J. N., and BuCKell, M. (1949). Lancet, 2, 451.

The authors describe the standard method used to detect latent fingerprints by applying a finely divided powder. Hydrargyrum cum creta $\boldsymbol{B}$.P., or grey powder, is used when the area to be examined is dark in colour. The powder is applied with a brush and the excess is brushed or blown off. In Great Britain, of all persons doing this work $90 \%$ use this particular powder. In the Lancashire County Constabulary 33 men are employed in the fingerprint squad and, in view of the degree of specialization, these men are exposed to the dust of grey powder for several hours each week. The authors, who examined this team, found tremor of the hands in 7 of them. In 3 cases it also affected the lips and tongue, and in 3 the eyelids. One man was severely affected. He became a nervous wreck, could not hold a glass of water without spilling it, and could not stand still or answer questions without embarrassment. Five of his teeth were loose and tremor was present in his hands, tongue, eyelids, and rectus abdominis muscles. Two men noticed that they were getting hypersensitive, had profuse sweating at the slightest mental stress, blushed easily, and were becoming short-tempered with children. They had tremor of the hands and eyelids. Loosening of the teeth was noticed in several cases. The 7 men affected had all been exposed to grey powder for periods varying from 4 to 13 years, and for times varying between 250 and 460 hours per annum. Urinary mercury estimations were found to be of no assistance in diagnosing individual cases or in estimating exposures, but the average excretion of the group was abnormally high. As regards prevention, the only practical solution is to stop the use of grey powder for developing latent fingerprints and to find a non-toxic substitute.

Gilbert Forbes. Occupational Poisoning by Alkyl Mercury Compounds.
Lundgren, K. D., and Swensson, A. (1949). J. industr. Hyg., 31, 190.

Alkyl mercury compounds are used mainly for disinfecting seed. Workers in four categories are therefore liable to be poisoned by them-those engaged in the production of germicides, those who treat the seed, those who sow the treated seed, and those who are employed at seed-control stations to make analyses for purity and fertility. The substance may be absorbed through the skin and alimentary tract as well as through the respiratory tract, so that air analyses of the factory premises are of limited value. Attention is directed in this paper to the urinary concentration of mercury, which gives a good indication of the risk, since when exposure is intense the mercury level in rises, and when the exposure is 
interrupted the amount of mercury excreted in the urine rapidly diminishes. The allowable urinary concentration of mercury is not established, but symptoms have appeared when the urine contained 50 to $100 \mathrm{ig}$. per litre of mercury.

Eight cases of poisoning are described, ranging from mild cases with symptoms of fatigue and neurasthenia to more severe cases with physical and mental defects. Control tests indicated that fatigue itself is of little value in assessing the risk.

K. M. A. Perry.

Bladder Lesions due to Aromatic Amines. Statistics and Prophylactic Measures. BARsotTI, M., and Vigliani, E. C. (1949). Med. d. Lavoro, 40, 129.

Over a period of 17 years cystoscopy was performed on 186 employees at two dyestuff factories, who worked in contact with benzidine, $\beta$-naphthylamine, $\alpha$-naphthylamine, or aniline, many being examined 7 or 8 times. Those examined had been in contact with the chemical concerned for at least one year or, in the case of aniline, 2 years. Where only a few men were employed on a hazardous process, all were examined, but where larger numbers were involved, those with changes in the urine, with bladder symptoms, or with many years' service were selected.

In order to minimize danger in the manufacture of benzidine, production was as far as possible limited to that of the sulphate salt instead of benzidine base. From this department, in which 106 workers were employed, 13 were examined for the reasons given. The cystoscopic findings in 5 of these were normal, 3 showed congestion, one had a papilloma, and 4 had carcinoma. The period of contact in those with tumours ranged from 10 to 26 years. In the $\beta$-naphthylamine section, 26 bladders were examined of which 8 were normal, 10 had congestion, 6 had papillomata, and 3 carcinomata. In the $\alpha$-naphthylamine section ( $3 \%$ of the $\beta$-compound appearing as an impurity) 30 men were employed, but some or all were at times working also with toluidine, anisidine, xylidine, chloroaniline and phenetidine; 23 bladders were examined, of which 14 were normal, 7 had congestion, and 2 had papillomata. In the aniline section 12 bladders were examined out of 19 ; of these 9 were normal and 3 showed congestion. It was difficult to estimate the total number of men who handled aniline occasionally outside the department, but possibly 600 men had some contact with it. Of these, 32 with symptoms were selected ; 7 bladders had sessile tumours, the others were normal. It was concluded that, in contrast to the other products, aniline had no appreciable carcinogenic property. The over-all minimum period of exposure preceding tumour formation was 4 years, the maximum 28 years. The maximum period between cessation of exposure and the diagnosis of tumour was 20 years. Symptoms were sometimes absent in those with advanced lesions.

Preventive measures should include the avoidance, when possible, of the manufacture of azo compounds and of substances in powder form. All processes of manufacture should be enclosed and the greatest possible cleanliness of the plant and of the individual should be encouraged. The more intelligent the operative the less the risk.

G. C. Pether.

Physiologic Response of Animals Exposed to Air-borne Ketene. Treon, J. F., Sigmon, H. E., Kitzmiller, K. V., Heyroth, F. F., Younker, W. J., and CholaK, J. (1949). J. industr. Hyg., 31, 209.

Ketene is a valuable acetylating agent which is being employed to an increasing extent in the manufacture of organic chemicals. In the factory it is handled entirely in closed apparatus, so that the risk is not great, but even so experiments to determine its toxicity have been carried out in mice, monkeys, rats, guinea-pigs, cats, and rabbits. The symptoms are severe dyspnœa and cyanosis, culminating in fatal œdema of the lungs, death being preceded by toxic irritation of the central nervous system. The effects are delayed, and are somewhat similar to, and of the same order of magnitude as, those occurring with phosgene. The highest concentration which failed to kill animals of a given species after a ten-minute period of exposure, and the least concentration that caused death when inhaled for the same brief period, were as follows, expressed in parts per million :

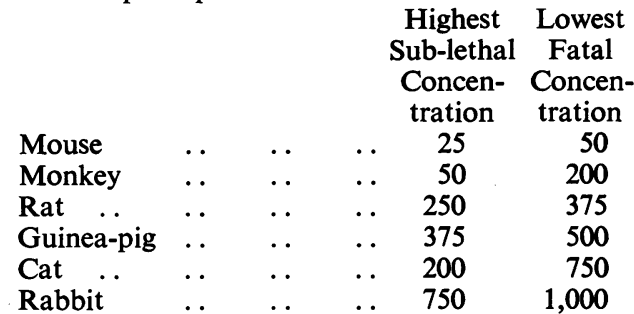

Experiments were also carried out to show the results of prolonged exposure to concentrations.

Necropsy revealed that there was no damage to the epithelium of the mucosa of the upper respiratory tract, and only rarely was there damage to the bronchiolar mucosa. The changes occurred notably in the lungs and were accompanied by acute lobular pneumonia, while after prolonged intermittent inhalation there appeared varying degrees of interstitial fibrosis, leucocytic and histiocytic infiltration, atelectasis, and emphysema.

Men who are exposed to ketene for short periods owing to their proximity to equipment from which the material may escape must be provided with readily available and adequate respiratory protection against inhalation of the substance. $\quad K . M . A$. Perry.

Acute Hemolytic Anemia due to Naphthalene Poisoning. A Clinical and Experimental Study. ZUELZER, W. W., and APT, L. (1949). J. Amer. med. Ass., 141, 185.

In 4 cases of fulminating hæmolytic anæmia occurring in children the authors attributed the condition to sucking naphthalene moth balls. The outstanding features of the 3 to 4 day illnesses recorded were lethargy, nausea, abdominal pain, vomiting, and pronounced hæmoglobinuria. There was no jaundice. The erythrocytes showed microcytosis, spherocytosis, and fragmentation. Bone marrow examination showed increased erythrogenesis of a mature kind. Transfusion and alkaliniza- 
tion brought rapid relief in each case. Studies in dogs confirmed the association between naphthalene and hæmolysis, Heinz bodies being found to appear before hæmolysis. Reference is made to the comparatively scanty attention paid in the literature to this form of poisoning and to its similarity to Lederer's anæmia. Unfortunately the exact-even approximate-dosage of poison in these 4 cases could not be estimated.

Keith Simpson.

The Protection of Personnel Engaged in Roentgenology and Radiology. Hunter, F. T., Merrill, O. E., Trump, J. G., and Robbins, L. L. (1949). New Engl. J. Med., 241, 79.

The death rate from leukæmia amongst radiologists is higher than the death rate in their medical colleagues. A total exposure dose of $0.3 \mathrm{r}$ per week is the accepted limit of safety, but whether this statement has much meaning at all is open to challenge. Ionizing radiations which penetrate to the blood-forming organs produce quite a different effect upon the body as a whole than radiation which is absorbed for the most part by the skin. The present work was undertaken with the object of establishing a more quantitative basis for relating radiation exposure to changes in the peripheral blood picture as an index of bone-marrow damage.

Measurements were made of intensity and quality of direct and scattered radiation from a phantom irradiated under conditions present during fluoroscopy. Contrary to general opinion, the 90 degree scattered radiation from a phantom is actually more penetrating than the direct incident beam. Film badges were used with four filters or windows, and measurements were made with "victoreen" chambers and pocket electrometers. Positions approximating to those of the roentgenologist's lower torso were chosen, as these were the points of greatest intensity of scattered radiation. Increasing the filter of the beam from 1.5 to $3 \mathrm{~mm}$. aluminium decreased the exposure of the patient per film and reduced to an appreciable extent the side-scatter received by the examiner without diminishing the luminescence of the screen.

It appears that optimal factors for screening procedure are : a current of $5 \mathrm{~mA}$ at $85 \mathrm{kV}$, and a tube filter of $3 \mathrm{~mm}$. aluminium. It is shown that all scattered radiation at voltage ranges between 50 and $140 \mathrm{kV}$ is sufficiently penetrating to reach the bone marrow. The patient can act as a filter and should be so used to reduce the intensity of the central scatter, the beam being centred as far distant as possible from the operating personnel ; field sizes should be kept as small as possible. Speed of examination, adequate aprons and gloves, and rooms with minimum back-scatter are all important.

A rigid programme was carried out at the Massachusetts General Hospital to determine the amount of radiation received by personnel. Those doing diagnostic work generally received less than $0 \cdot 1 \mathrm{r}$ over a two-week period. Radium workers showed a greater exposure, but still less than $0.3 \mathrm{r}$. The use of film badges will reveal individual carelessness when it occurs, and will also have a psychological effect on those wearing them, in making them avoid undue exposure. I. G. Williams.
Conditions of Work and Industrial Hygiene Measures in Production of, and Manufacture from, Chlorvinyl Plastics. Tribukh, , S. L., Tikhomirova, N. P., Levina, S. V., and Kozlov, L. A. (1949). Gigiena No. 10, 38.

Chlorvinyl plastics are by-products of polymerization of the chlorvinyl resin. The manufacturing process involves production of carbon dioxide and vapour of organic chlorides, which affect workers employed in this industry. Exhaust ventilation arranged vertically just above the work-benches secures the best hygienic conditions, but all methods of ventilation so far tried have failed to protect workers adequately against ill effects of the process.

Medical examination of personnel showed that the most frequent finding is of a precipitate upon the mucous membranes which forms a very thin layer, quite difficult to remove. Hyperæmia of the upper respiratory passages was found in 17 out of 18 cases investigated, chronic bronchitis in 13, gastritis in 10, and colitis in 2 cases. In all cases there was also some degree of anæmia. An acneiform dermatitis was not uncommon.

Personnel engaged in manufacture of chlorvinyl plastics should be provided with appropriate underwear and a special overall for protection of the body. The former should be thoroughly ventilated before and after working hours.

E. W. Collis.

The Rapid Elimination of the Eschar in Burns by Employment of Pyruvic Acid. Russo, A. D. C. (1949). Rev. brasil. Cir:, 18, 63.

A pyruvic acid paste has been used by the author for the treatment of 2 nd and 3rd degree burns in a series of 14 patients. Treatment was started 3 to 16 days after the burn was sustained and with an average of three dressings over a period of a week all the scabs fell off. The acid dressings were followed by two or three daily saline dressings to remove traces of the acid, and skin grafting was then carried out successfully. The author believes that the effect is due to the constantly maintained $p \mathrm{H}$ of the solution ; other acids with identical $p \mathrm{H}$ were used with similar effect on the scabs, but they were irritant to the healthy tissues. It is claimed that this is a simple, quick, safe, and comfortable method of preparing burns for skin-grafting.

Jorge D. Mineiro.

Hepatitis among American Occupation Troops in Germany : A Follow-up Study with Particular Reference to Interim Alcohol and Physical Activity. GARDNER, H. T., Rovelstad, R. A., MoOre, D. J., Streitfeld, F. A., and Knowlton, M. (1949). Ann. intern. Med., 301009.

By an elaborate series of follow-up investigations on American soldiers serving in Germany the authors were driven to conclude, contrary to orthodox views, that physical exertion and moderate indulgence in alcohol do not render men convalescent from infective hepatitis specially liable to relapse or residual hepatic inefficiency. Very impressive statistics are presented in support of this theme, and the report of a "battery" of hepatic tests 
on 114 patients is given in full. The fallacies are most fairly stated.

[British readers will be familiar with the articles of Davis (Practitioner, 1949, 162, 173) and of Tunbridge (ibid., 1949, 162, 182), both of whom are more cautious, and with the warnings originally made by Hartfall (Brit. med. J., 1944, 2, 587).]

G. F. Walker.

Treatment of Toxic Agranulocytosis, with Special Reference to That Due to Benzene. DuVOIR, M., DEROBERT, L., and Gaultier, M. (1949). Arch. Mal. prof., 10, 5.

This paper describes a number of disconnected clinical and experimental results ; by treatment of human subjects suffering from blood dyscrasias after exposure to benzene and of guinea-pigs and rabbits poisoned with benzene, the authors sought to assess the value in treatment of methionine, cystine, pyridoxine, folic acid, and penicillin. [The revelance of the animal experiments to the clinical studies is difficult to follow, especially as the authors remark that air concentrations of benzene vapour causing symptoms in man do not affect guineapigs.] Agranulocytosis may be a clinical entity of unknown origin which needs for its onset the presence of some other factor (a deficiency or infection) besides exposure to a poison.

T. A. Lloyd Davies.

Carbon Monoxide-Hemoglobin Levels of Workers Employed in Airplane Engine Repair Shops. CHINN, H. I. (1949). J. industr. Hyg., 31, 258.

Poisoning due to Tetraethylpyrophosphate. FAUST, J. (1949). J. Amer. med. Ass., 141, 192.

Studies on the Toxicity and Pharmacological Action of Sodium N-p-Chlorophenyldiazothiourea (promurit). Cochran, K. W., and DuBois, K. P. (1949). J. Pharmacol., 97, 105.

The Physiological Response of Animals to Trichloroacetonitrile Administered Orally, Applied on the Skin or Inhaled as a Vapor in Air. Treon, J. F., KITZMiller, K. V., Sigmon, H., DUTRA, F., and YounKers, W. (1949). J. industr. Hyg., 31, 235.

\section{INDUSTRIAL PHYSIOLOGY}

The Effect of Water and Salt Intake on Prickly Heat. Horne, G. O., and Mole, R. H. (1949). Lancet, 2, 279.

Ten men suffering from prickly heat underwent an investigation during the summer of 1947 in the Royal Air Force General Hospital in Karachi. Their food was cooked with an unspecified but "liberal" amount of salt, and their usual intake of water appears to have been adequate. An increase of the water intake by 8 to 12 pints (4.4 to 6.6 litres) daily was followed within 2 to 10 days by a marked improvement or complete disappearance of prickly heat in eight subjects and by a worsening of symptoms in the other two. Five of the subjects whose condition had improved then reduced their intake of water to what it had been before the experiment and increased their sodium chloride intake by 10 to $15 \mathrm{~g}$. daily ; they all suffered from severe recurrence of prickly heat, but this disappeared for a second time when the extra salt was stopped and an extra 8 to 12 pints of water was drunk instead. In one subject prickly heat disappeared three times after such a high intake of water, and it reappeared twice after a high intake of salt. Another subject had severe attacks of prickly heat after taking sodium chloride, sodium dihydrogen phosphate, and sodium citrate but not after taking ammonium chloride, and the authors suggest that retention of sodium may have helped to cause prickly heat. Electrolyte and water balance studies, however, were not made, and the paper contains no data either on the output or the total intake of any of these substances. Unpublished observations by other Royal Air Force medical officers in India and Pakistan are also given, and these bear out the possibility that a high fluid intake is beneficial in prickly heat and that a high sodium chloride intake aggravates that condition.

E. M. Glaser.

Linear Acceleration and Deceleration as Factors Influencing Nonvisual Orientation during Flight. CLARK, B., and Graybiel, A. (1949). J. Aviat. Med., 20, 92.

Disorientation in flight may occur when visual indications of position in space are insufficient. Part of the disorientation may be due to non-visual stimuli. Thus if the pilot is subjected to angular, linear, or radial accelerations, stimuli to the non-auditory labyrinth and kinæsthetic stimuli may give him a false impression of his position. The illusions due to angular and radial acceleration have been the subject of previous studies. In this study the authors have investigated the effect of linear, that is, fore-and-aft, acceleration.

Observations were carried out, in flight, in the rear cockpit of an SNJ-6 aircraft. Visual aids to orientation were eliminated by covering the observer's head with a black cloth. In half the trials the observer faced forward and in the remainder he faced to the left. A continuous recording was made of the subject's verbal report of any apparent change in position. Changes in linear acceleration, which were recorded by means of three accelerometers, one for each of the major ones, were brought about by the pilot varying the setting of the throttles and flaps. The results showed that the resultant of the force of linear acceleration and the force of gravity acting on the body produced a strong sensation of tilt. The sensation of tilt varied in degree with the magnitude of the acceleration, but in all cases the subject's estimation of the angle of tilt in degrees was greater than the change in direction of the resultant force. These sensations of tilt, in the absence of sufficient visual cues, would be interpreted as a change of pitch of the aircraft and represent an added source of confusion resulting from accelerative forces acting on the body during normal flight. 


\section{INDUSTRIAL LUNG DISEASE}

Tomographic Studies of the Pulmonary Hila in Silicosis. ZANetTI, E., and PontI, C. DE (1949). Med.d. Lavoro, 40, 197.

Changes in the hilar shadows, seen in radiographs of the lung in cases of silicosis, have been analysed by means of tomography. In cases in which the plain radiograph shows enlarged hilar shadows, the enlargement of hilar and parahilar lymph nodes may be clearly demonstrated in the tomographs. Moreover, in cases in which extensive parenchymatous change and dislocation of the hila prevent the hilar shadows from being seen on the plain film, the extent of dislocation and of involvement of the nodes may be assessed tomographically. The authors state that the main bronchial branches are rarely stretched or compressed in silicosis and that the degree of enlargement of the various groups of hilar lymphatic nodes is not related to the degree of the silicotic involvement of the lung parenchyma.

A. Orley.

Mortality and Survival Rates in Males with Silicosis or Silico-tuberculosis. TURner, H. M., and MARTIN, W. J. (1949). Brit. med. J. 2, 1148.

A study was made of survival rates after age 40 in 466 cases of silico-tuberculosis and 348 of silicosis drawn from various industries in Sheffield. It is shown that the proportion of silico-tuberculosis to silicosis varies in different trades, being, for example, low in coal miners (possibly, according to Cummins, because coal dust acts as an adsorbent of tuberculin). The results confirm the belief that the prognosis in silico-tuberculosis is worse than in uncomplicated tuberculosis, particularly when tuberculous infection occurs at the onset of the silicosis and in the younger patient. Difficulties in the application of collapse therapy and other active measures in silicotuberculosis are discussed, and one case is quoted in which streptomycin was used with good immediate effect.

The survival rate in uncomplicated silicosis, as determined here, is comparable to the standard up to the age of 51 , after which it deviates until at age 65 it is $27 \%$ below the standard. The causes of death in 610 of the cases in the series are given. [In 92 cases the patient is stated to have died simply of "silicosis", and the actual cause of death is not clear.] It is concluded that, from age 40 , there is a reduction in life-expectation of 13 years in the silico-tuberculosis group, and of 8 years in the silicosis group.

L. W. Hale.

" Egg Shell " Calcifications in Silicosis. Grayson, C. E., and Blumenfeld, H. (1949). Radiology, 53, 216.

Out of a total of 88 cases of silicosis, the authors demonstrated "egg-shell" calcification in 37 cases. These areas of calcification are circular or ovoid in shape, the calcium being deposited toward the periphery of the shadow. They are only found in lymph nodes. These calcifications occur long after the original exposure and especially in the milder cases. The authors contend that these calcium deposits occur as a result of the action of silica without any superimposed tuberculous infection.

L. G. Blair.
Studies on Aerosols. VI. Effect of Aluminium Powder and of $\mathrm{NaCl}$ Aerosols upon the Pulmonary Deposition of Silica Dust (Long Exposure). (In English.) Dautrebande, L., Alford, W. C., Irwin, D. A., Mitchell, E. R., Thompson, E. C., Weaver, F. L' and Wood. E. J., (1949). Arch. int. Pharmacodyn, 80, 388.

The fact that aerosols of water or of solutions of sodium chloride can cause aggregation of fine dust particles in the air suggested that dispersion of aerosols in dusty atmospheres might reduce the amount of dust deposited in the peripheral parts of the lungs of animals. It was first confirmed that rabbits and rats subjected to prolonged exposure to aerosols of 5 to $10 \% \mathrm{NaCI}$ solutions suffer no ill effects. Groups of rabbits were repeatedly exposed to atmospheres containing silica dust or silica plus aluminium, the exposures being for 6 hours daily and ranging from 24 to 183 days. The animals' lungs were later examined. The silica contained about $1 \%$ of iron, whose presence was useful in the histological studies ; the iron concentration approximated to that in the dust found in mines whose ores, in dust form, have been known to cause silicosis. The apparatus and methods are described. The saline aerosol used contained $75 \mathrm{mg}$. NaCI in a cubic metre of air.

Not only was the total weight of silica or of silica and aluminium present in the lungs less in animals exposed to dusty atmospheres containing saline aerosols than in those exposed to dust without aerosols, but the aerosoltreated silica dust did not tend, like untreated dust, to accumulate in larger alveoli. Most of the aerosoltreated dust was found to be in the large bronchi. The clinical importance of these observations cannot be assessed until the results of field trials are available.

The formation of large aggregates of dust when the silica-laden atmosphere was mixed with saline aerosol was confirmed by electron microscopy. By means of an intense electron microscope beam, the particles of silica dust and the salt crystals could be differentiated. The amount of dust collected in a given time is much greater when it is mixed with an aerosol of $\mathrm{NaCl}$.

Derek R. Wood.

Electrocardiographic Studies in Anthracosilicosis. LANG, L. P. (1949). W. Va med. J. 45, 303.

This study is based upon the electrocardiographic findings in 148 coalminers, aged 24 to 72 years (mean 53 years), who had been exposed to risk of anthracosilicosis for periods ranging from 6 months to 44 years (average 28.6 years). The results of the investigation of pulmonary function in these men have been reported elsewhere (Amer. Rev. Tuberc., 1949, 3, 270). In each case the three standard limb leads were recorded and at least three precordial leads, usually CF2, CF4 and CF5. Katz's criteria were used for the diagnosis of right ventricular hypertrophy. Electrocardiographic evidence of right heart strain was found in 36 cases $(24 \%)$, which, although not apparently related to the presence of radiological evidence of pulmonary fibrosis, was closely related to the degree of emphysema and of decrease in maximal breathing capacity from the predicted normal. In general, the lower the mean partial pressure of 
arterial oxygen, the greater the incidence of right heart strain. An interesting point is that there was little difference in the incidence of electrocardiographic evidence of right heart strain between those patients with normal or borderline radiographs ( 3 out of 14 , or $21 \%$ ), those with 1 st stage silicosis (8 out of 25 , or $32 \%$ ), and those with 3rd stage silicosis ( 23 out of 80 , or $29 \%$ ). It is also noteworthy that there was no appreciable electrocardiographic evidence of right heart strain until the maximal breathing capacity was decreased by more than $50 \%$ of normal.

[It is unfortunate that none of these changes are analysed in relation to the age of the patients, especially in view of the wide range of ages covered.]

William A. R. Thomson.

Pneumoconiosis in Graphite Workers. DUnNer, L., and Bagnall, D. J. T. (1949). Brit. J. Radiol, 22, 573.

The authors report their findings in the examination of workmen employed in a factory producing " black lead". The diagnosis of " graphite lung " can be established only by radiological examination, as the clinical signs and symptoms may be slight and are non-specific. There is no relation between the duration of exposure to graphite dust and the date of onset or the extent of the lesions. This may indicate an individual susceptibility. No single radiological finding is pathognomonic of graphite lung, but the miliary "snow-storm" pattern, with the subsequent formation, by coalescence, of large, sharply defined masses is mentioned particularly. The various changes may be seen in both lungs or in one lung only, in contrast to other forms of occupational pneumoconiosis.

The correlation between $x$-ray and post-mortem findings in one case is discussed. The marked fibrosis seen on microscopical examination was probably attributable to silica, although it is possible that graphite also played a part. Large dense masses seen radiologically, which were presumed to be solid and due to coalescence of small fibrotic nodules, were found post mortem to be sacs completely filled with a black fluid. On chemical analysis this fluid, which was sterile on culture, was found to contain $3.5 \%$ of carbon, but no silica. The authors postulate a process of increasing fibrosis around localized graphite accumulations, with gradual limitation of the blood supply and consequent colliquative necrosis, and suggest that subsequent mechanical contraction of the fibrous tissue would result in the formation of spherical cysts.

A. S. McLean.

"Neo-epinine" in the Dyspnoea of Coal-miners. Robertson, C. K. (1949). Brit. med. J., $2,961$.

The 58 coal-miners investigated were between 33 and 65 years and complained of shortness of breath on exertion. In all but 14 there were radiological signs of pneumoconiosis in different degrees; in the majority (29) there was partial distribution of linear shadowing and indication of early nodulation. For the first week of observation they were given inert tablets. The vital capacity during this week did not show a significant change. The subjects then received $20 \mathrm{mg}$. tablets of isopropylnoradrenaline three times daily for one week, and the vital capacity increased on the average by 236 $\mathrm{ml}$. In 44 cases there was subjective improvement. [As the actual vital capacity of the subjects and the variation of its increase are not given, it is difficult to judge whether the observed average increase represents an important objective improvement. Its smallness may indicate that in pneumoconiosis (as in emphysema) bronchial spasm plays a smaller part in the reduction of vital capacity than in ordinary asthma.]

H. Herxheimer.

Chronic Pulmonary Granulomatosis. Report of Ten Cases. DeNardi, J. M., Ordstrand, H. S. Van, and Carmody. M. G. (1949). Amer. J. Med., 7, 345.

Chronic pulmonary granulomatosis has many synonyms-for example, miliary sarcoidosis, chronic granulomatous pneumonitis, delayed chemical pneumonitis, and beryllium sarcoiditis. It has been attributed to work with beryllium, but its ætiology is still uncertain. Ten more cases are described: 4 of the patients worked in a plant producing beryllium, 4 lived near the plant, and 2 lived apparently beyond the range of atmospheric contamination. Contact with beryllium could not be proved in the last 2 cases. The onset of the illness was insidious, with a cough which became paroxysmal, substernal pain, acrocyanosis, and clubbing of the fingers and toes. Physical examination revealed loss of weight, diminished chest expansion and vital capacity, a resonant parcussion note, and crackling rales in the hilar region. There were no skin or glandular lesions, and the blood count, erythrocyte sedimentation rate, and albuminglobulin ratio were all normal. On radiological examination a typical ground-glass appearance of the lungs and normal bones in the hands were found. Beryllium was present in small amounts in the urine of 2 patients and was absent in 2 more.

The prognosis of the disease is uncertain. One patient, first seen in 1945, is still alive, and 3 other patients have improved clinically. Two patients in the present series died and necropsies were carried out. Chronic granulomatous interstitial pneumonitis and lymphadenitis were found. In both cases there was parenchymatous degeneration of the liver, with granulomatous areas in one. No beryllium was found in the tissues in one case, and in the other the results of analysis were equivocal. There is no specific treatment. Restriction of the patients' activity, because of the reduced vital capacity, is important and " benadryl" may help to relieve the troublesome cough.

Arthur Willcox.

Acute Pneumonitis in a Beryllium-worker. Royston, G. RIDDELl (1949). Brit. med. J., 1, 1030.

The author describes the occupational history and the clinical and radiological appearances of a case of acute pneumonitis in a laboratory worker aged 30 who had been engaged for some weeks in mixing powders for lining fluorescent tubes. This mixture contained beryllium and zinc and, in general, such mixtures are known under the trade name of "phosphor". The principal symptom was a cough accompanied by marked dyspnœa. 
Rhonchi fine in character were generally distributed throughout both lungs. Sputum examination for tubercle bacilli was negative. The radiographs showed a millet-seed mottling distributed-over both lung fields, suggestive of miliary tuberculosis. In 8 months this picture had completely resolved and the radiograph of the lungs appeared normal. Complete clinical recovery is reported.

The author details the types of lung involvement which may follow the inhalation of the beryllium-containing phosphor, and discusses the differential diagnosis.

$$
\text { A. J. Amor. }
$$

The Effects of Kaolin on the Lungs of Rats. KING, E. J., Harrison, C. V., and NAGelsChMidT, G. (1948). J. Path. Bact., 60, 435.

The effects were studied of insufflation of suspensions of kaolin through the exposed trachea into the lungs of black-and-white rats under light ether anæsthesia. Each rat weighed about $200 \mathrm{~g}$., and 1 to $1.2 \mathrm{ml}$. of suspension in saline containing 3\% milk was used in the experiment. The materials insufflated were South Wales kaolin, untreated Cornish kaolin, and ignited Cornish kaolin, quartz being used as a control. [For details of the preparation of the kaolins, the original paper should be consulted.] Each sample was injected into a group of 10 rats.

Quartz produced typical silicosis, but the kaolins evoked only a very mild reticulin reaction; this was slightly more pronounced with the ignited Cornish kaolin than with the other samples. R. B. T. Baldwin.

\section{INDUSTRIAL SKIN DISEASES}

Cutaneous Granuloma from Accidental Contamination with Beryllium Phosphors. NichOL, A. D., and Dominguez, R. (1949). J. Amer. med. Ass., 140, 855.

The increasing use of fluorescent lamps, sign tubes, and radio appliances has multiplied the chances of accidental contamination of the skin and subcutaneous tissues with beryllium. The authors describe 2 cases in which indolent skin lesions developed after accidental laceration with broken fluorescent lamps. Both patients were fluorescent lamp workers who, after $4 \frac{1}{2}$ and 6 years of exposure to beryllium respectively, had developed chronic lung disease, with loss of weight, dyspnœa on exertion and cyanosis, and both had the typical $x$-ray appearance of delayed chemical pneumonitis. There was a history in one of accidental lacerations in the suboccipital region from broken lamp fragments $8 \frac{1}{2}$ years previously. The lesions healed promptly, but later broke down and suppurated repeatedly. The other patient developed a painful swelling under an old scar on the elbow while under treatment for the lung disease. She then admitted to laceration of the skin by fragments of a fluorescent lamp 18 months previously. Sections of the abnormal tissues showed small, circular, encapsulated granulomata, some partly or completely hyalinized, but without caseation. Beryllium was found in the abnormal tissues by spectrographic means, no beryllium being found in control tissues. In one case the quantity of beryllium in consecutive slices of scar tissue varied between 2.1 and $79.4 \mu \mathrm{g}$. per g. of tissue and an attempt is made to correlate the beryllium content of each with the number of granulomata present per sq. $\mathrm{cm}$. of section. The authors believe the pulmonary lesions to have been caused entirely by exposure to air contaminated with beryllium, and removal of the affected skin made no difference to the lung disease. Since, as the first case shows, beryllium can persist in skin lesions for $8 \frac{1}{2}$ years despite repeated ulceration and suppuration, wide excision is required in the treatment of wounds contaminated with beryllium. [These cases are remarkable in that disease resulted from separate local implantation of beryllium into the skin of patients who were also victims of the specific occupational lung disease.]

\section{J. N. Agate.}

Beta Ray Burns of Human Skin. Knowlton, N. P., Leifer, E., Hogness, J. R., HempelmanN, L. H., Blaney, L. F., Gill, D. C., OAKes, W. R., and Shafer, C. L. (1949). J. Amer. med. Ass., 141, 239.

From the Los Alamos Hospital, New Mexico, the authors describe 4 cases of beta-ray burns of the hands which occured during atomic energy tests at Eniwetok Atoll. The dose of beta rays received in each case by the patient was not measured at the time of exposure, but was calculated on the basis of film-badge and pocket ionization-chamber readings for gamma rays. These indicated a beta-ray dosage of 3,000 to 16,000 roentgen equivalents on the outer surface of the skin over a period of about one hour.

The clinical course was divided into four distinct phases: (1) Initial erythema and œdema with blanching of the areas which received the greatest amount of exposure, beginning with the initial exposure, reaching a peak in 48 hours, and then subsiding rapidly. (2) A period of relative absence of signs and symptoms lasting for 3 to 5 days. (3) A phase first manifested by the development of a secondary erythema, sometimes complicated by extravasation of blood, the areas affected becoming vesicular 8 to 12 days after exposure. In the following 2 weeks the erythema spreads, with subsequent formation of more vesicles and bullae, and then the active process becomes arrested and the bullae begin to dry and desquamate. At this stage epithelization occurs over all areas where the vascular supply has not been seriously damaged. (4) A chronic stage in which areas of serious vascular damage remain unhealed. In less seriously damaged areas an atrophic epidermis, lacking in hair and sebaceous glands, is formed. Secondary ulceration, hyperkeratosis, talangiectases, and malignant changes (which may occur many years later) are included in this phase.

The 2 men who received the largest amounts of radiation reported a sensation of tingling and itching at the time of exposure. Further effects noted were a retardation of nail growth to about one half of the normal rate and a slight depression in the nail which was formed at the time of the exposure. In 3 cases the dorsal surfaces of the fingers showed an apparently permanent increase in pigmentation. During the first few days after exposure there was excessive sweating of the palms, 
but after about a week there was a marked lack of perspiration which persisted for many weeks. Significant changes were found in the total leucocyte and neutrophil granulocyte counts, in the number of refractive granules in the cytoplasm of the lymphocytes and in the erythrocyte sedimentation rate. A. S. McLean.

The Cold Permanent Hair-waving Process. A Dermatologic and Clinical Study. Behrman, H. T., Combes, F. C., Weissberg, G., Mulinos, M. G., and Hurwitz, M. M. (1949). J. Amer. med. Ass., 140, 1208.

The effects of the lotion used in a cold permanent hairwaving process were investigated in 1,200 people. The main active ingredient was ammonium thioglycolate with potassium bromate as "neutralizer". Paired patch tests were performed with the fresh lotion, lotion which had stood for a year, a $2 \%$ solution of potassium bromate, mixtures of lotion and neutralizer, and solutions of ammonium thioglycolate of various strengths at $p \mathrm{H} 9 \cdot 2$. Subjects were chosen who had had no previous contact with the solutions, and others with varying lengths of contact with it. The tests were repeated 2 to 4 weeks afterwards. Patch tests with the lotion were carried out on 286 people (half of each sex) with various dermatoses. One gave a weakly positive reaction. On re-testing 109 of them, 2 gave weakly positive reactions. Patch tests were carried out on a group of 863 subjects who had had previous contact with the solutions. Of these, 16 gave a positive reaction and in 2 this remained positive on retesting (one was not tested a second time).

The scalps of 174 people who were having their hair waved were examined. No ill effects were found. Because of the suggestion of a possible hepatotoxic effect, a large range of tests were performed on a group of people, including $\mathbf{7 2}$ factory workers in daily intimate contact with the lotions and chemicals. Thorough blood and urine examinations and three liver function tests were carried out, but no abnormality attributable to these substances was discovered. The authors conclude that these lotions have a low sensitizing potential and that they are safe for general use. E. Lipman Cohen.

A Clinical Appraisal of the Cold Wave Process. CoHEN, M. H. (1949). Arch. Derm. Syph., Chicago, 60, 14.

The author reviews recent literature on the cold wave process. He states that the active constituent of most cold wave solutions is thioglycollic acid. Other ingredients are ammonia, perfume, and colouring matter. The acid content should be 4 to $7 \%$ and the $p \mathrm{H}$ between 9 and $9 \cdot 5$.

The opinion of the author is that the process is dangerous if used at home, but less so if administered by a competent hairdresser. If the cold wave is done by an expert the most complicated directions can be more easily followed and the neutralizing solution more easily applied. Signs of scalp irritation can be more readily seen and the hands of the operator can be better protected. The advisability of repeating the process as frequently as every 3 to 4 months, as recommended by the manufacturers, is questioned. A number of cases of various types of skin irritation following the use of cold wave solutions are described. The author states that it is his clinical impression that the thioglycollic acid solution can have the effect of aggravating various dermatoses and should not be used on women who suffer from dermatitis venenata, seborrhoeic dermatitis, psoriasis, or alopecia areata; nor should it be used on anæmic subjects or in cases of liver disease. Cases of contact dermatitis on the hands of cold wave operators are described and the use of gloves is advised. H. S. Laird.

External Use of " Carbitol Solvent", " Carbitol " and Other Agents. Meininger, W. M. (1948). Arch. Derm. Syph. Chicago, 58, 19.

It is said that these chemicals are added to many cosmetic preparations because of their "vanishing" effect. Renal and hepatic damage has been demonstrated in experimental animals following ingestion, injection, and external application of "carbitol" and "carbitol solvent". This prompted the author to investigate their possible hazards on human skin. Patch tests, however, showed that monoethyl ether of diethylene glycol does not possess high sensitizing powers for human skin and is probably seldom responsible for contact dermatitis from cosmetics. Carbitol solvent and carbitol appeared to be innocuous in lotions and ointments, even after prolonged use in high concentration. Absorption in human beings was not demonstrable. In fact, the addition of carbitol to lotions and ointments is recommended in order to make them more uniform, to retard drying, and to enhance their emollient effect. E. W. Prosser Thomas.

The Fibrin-Coagulation Method, a New Procedure for Treating Extensive Burns. FRANK, G. (1949). J. int. Chir., 9, 443.

This is a preliminary report on a method of treating extensive burns of the more severe degrees by precipitating the fibrinogen of the plasma with the help of thrombin, which is sprayed on the wounds. Fibrin is formed and serves as a physiological cover and the basis for a scab which is left in situ. In order to prevent infection penicillin is mixed with the thrombin of the spray and in addition given systemically. Dressings, consisting of sterile "vaseline" gauze only, are not changed for a fortnight; second-degree burns are then found to have healed and third-degree burns to be in the advanced stages of healing.

The authors, who intend to improve this method further, were impressed by the relatively rapid repair, the lack of severe general reaction, and the absence of infection and of pain. Cosmetic results are said to have been excellent, even on face and hands. L. Michaelis.

Occupational Leukoderma. A Report of Six Cases Observed in a South African Factory. LockhART, R. J. J., and Loewenthal, L. J. A. (1949). S. $A f r$. med. J., 23, 867.

Oral Bismuth Therapy in Dermatology. Miller, T. H., and Delaney, J. R. (1949). Arch. Derm. Syph., Chicago, 60, 196.

The authors report favourably on the use of sodium bismuth triglycollamate (" bistrimate") by mouth in the 
treatment of warts of various types, condyloma acuminatum, lupus erythematosus, lichen planus, and scleroderma. The dose for adults was one tablet (equal to $75 \mathrm{mg}$. metallic bismuth) 3 times a day after meals for 3 days and 2 tablets 3 times a day subsequently for varying periods. The dose for children was estimated according to age and weight. The drug was well tolerated. Complete cure is stated to have occurred in 2 cases of subacute disseminated lupus erythematosus and in one case of acute lupus erythematosus and associated polyarthritis.

E. W. Prosser Thomas.

Seabather's Eruption. SAMs, W. M. (1949). Arch. Derm. Syph. Chicago, 60, 227.

The author describes an acute eruption, consisting of erythematous wheals and inflammatory papules, occurring within a short time of bathing in Florida waters. The rash is predominantly under the bathing garment, especially on the buttocks and waist. No penetrating parasites were found and the eruption is regarded as distinct from that of contact dermatitis from hydroids and coral and from "swimmer's itch", which occurs only in fresh water and is stated to be due to penetration of the skin by Schistosoma cercariae. The possible cause is the subject of speculation both by the author and in the discussion which followed the presentation of his paper. E. W. Prosser Thomas.

Clinical Observations on the Use of Dibromopropamidine (M \& B 1270) for Surface Infections, with Particular Reference to Bacillus proteus vulgaris and Pseudomonas pyocyanea. CHAMPION, A. H., and MCDowall, A. (1949). Brit. J. plast. Surg., 2, 57.

While most staphylococci and streptococci can be removed from a raw surface by penicillin, no substance has yet been found which controls Bacillus proteus and Pseudomonas pyocyanea, which are common contaminants of third degree burns and open wounds. The author describes 12 cases in which dibromopropamidine di-isethionate ("M and B 1270 ") was used, either as a powder or in a water soluble cream made from carbo wax and propylene glycol, the concentrations of dibromopropamidine used being $15 \%$ and $3 \cdot 5 \%$. After initial swabs had been taken and the bacteriology determined, either (1) the powder was used and dry crusts allowed to form, this being taken as an indication that the area was sterile, or (2) the cream was used and sterility determined by bacteriological examination.

Although small areas only were treated because of possible toxic effects (of which none were encountered), sterility was obtained in all of the cases described. In the majority this was followed by satisfactory grafting and in a few by spontaneous healing. [If further work on dibromopropamidine supports the above findings a very serious problem will have been eliminated.]

\section{Rainsford Mowlem.}

Contact Dermatitis Due to Procaine: A Common Occupational Disease of Dentists. LADEN, E. L., and Wallace, D. A. (1949). J. invest. Derm., 12, 299.

Allergic eczematous contact dermatitis from local analgesics is stated to be so common among dentists as to constitute an occupational hazard. Of a large number (569) of dentists known to suffer from this ailment who ware questioned about the exact substances suspected of causing their dermatitis, local analgesics were listed by $64.5 \%$; other substances suspected included soap and water, acrylic resins, photographic developers, formaldehyde, rubber or latex, and phenol.

Clinical and allergic studies were made on 10 dentists with chronic dermatitis, 9 of whom were shown by patch testing to be hypersensitive to local analgesics; 8 of these were subjected to further tests. The distribution of the dermatitis in all cases was characteristic, namely, on the distal phalanges of the first three fingers of the left hand-apparently due to the insertion of these fingers in the patient's mouth during infiltration with the analgesic. As a result of patch-testing with various local analgesics and related chemicals, the authors conclude that hypersensitivity to one of the members of the procaine group leads in most cases to hypersensitivity to all members. With one exception, hypersensitivity was restricted to the procaine group and was not present to local analgesics differing markedly from procaine in the chemical structure of their nucleus or side chain, such as "metycaine" and "intracaine". E. W. Prosser Thomas.

\section{GENERAL}

Peptic Ulcer in Factory Workers : A Socio-medical Pilot Survey. Evans, D. G. (1948). Publ. Hlth. Lond., 62, 203.

This paper comes from the Institute of Social Medicine at Oxford, and serves to emphasize further the extreme difficulty of research in sociological medicine. In general, the results of the investigation reported here are disappointing, but the value of the survey, as the author remarks, lies more in pointing out the difficulties and problems concerned. Subjects were chosen for investigation out of a factory population, and were divided into two groups-one of volunteers with stomach trouble, and the other of controls. The series included very few women, but the proportion of men to women in the factories concerned is not given. Some of the factors studied were as follows: (1) degree of work, physical and mental; (2) position at work; (3) tobacco-smoking; (4) alcohol consumption; (5) use of leisure; foods, habits, and occupational history. So far as possible comparison was made between the gastric and the duodenal ulcer groups, and between these and the controls. An attempt was also made to relate constitution, worry, and heredity in the ulcer cases and any factors associated with the onset of symptoms or relapses as judged by the patients themselves. The numbers concerned were 122 males with peptic ulcer and 182 dyspepsia-free controls.

Many criticisms can be offered even in this careful study as to the validity of conclusions drawn, but the author wisely resists any temptation to depart from accurate statistical methods. The frequent habit of going to work without breakfast is rightly noted, and the tendency of patients with ulcer to do their work in the sitting position rather than upright. A definite tendency 
appeared to exist amongst patients to give up pipesmoking in favour of cigarettes, and the figures suggest that smoking may predispose to or aggravate ulcer. No striking differences were found as regards shift work, irregular meals, degree of mental effort, or the influence of heredity in these cases.

[This paper deserves study in spite of its negative findings, and in particular is a corrective of much casual and loose research in ulcer causation. It is clear that, while not insurmountable, the problems involved are both numerous and complicated.]

Thomas Hunt.

Rift Valley Fever. Accidental Infections among Laboratory Workers. SMITHBURN, K. C., MAHAFFY, A. F., Haddow, A. J., Kitchen, S. F., and Smith, J. F. (1949). J. Immunol., 62, 213.

The history, symptoms, and diagnosis of 8 cases of laboratory-contracted infection with Rift Valley fever among white and coloured personnel are described in detail. Headache, backache, anorexia, prostration, and fever lasting 2 to 6 days were observed. All patients recovered, without any permanent sequelæ, after a period of incapacity for work varying from 2 to 28 days. The virus was isolated from the blood of all of them during the febrile stage of the disease, and a neutralizing antibody was demonstrated in all cases during convalescence. Two patients had vivax malaria infection at the onset of Rift Valley fever infection. The first-day serum of one patient contained $1,500,000$ intracerebral LD 50 of the virus after 82 days' storage in the refrigerator; viable virus was found in the same blood after storage for 2 years in the fluid state. Viable virus was present in the sera of other patients after even longer storage (up to 1,048 days) in the refrigerator. Three African workers, who were not known to have had the disease, proved immune to the virus; this is interpreted as an indication that these 3 individuals passed through an attack of subclinical infection resulting from contact with the virus in the laboratory. H. P. Fox.

The Disinsectisation of Aircraft: Recent Progress of Work in the United Kingdom and Colonies. WhITTINGhaM, H., and Galley, R. A. E. (1949). Mon. Bull. Min. Hlth., 8, 186. 